\title{
ADULTS IMPACT ON THE RELIABILITY AND SUGGESTIBILITY OF CHILDREN'S EYEWITNESS TESTIMONY
}

\author{
Dr. Sc. Eda ERMAGAN-CAGLAR* \\ Prof. Dr. Nese KOCABASOGLU** \\ *Correspondent Author: University of Northampton, Faculty of Health and Society Department of Psychology, \\ eda.e.caglar@northampton.ac.uk \\ **University of Istanbul. Medicine faculty, Department of Psychiatry, nesekocabasoglu@superonline.com
}

Article history:
Accepted 19 September 2019
Available online 31 December 2019
Keywords:
Child
eyewitness testimony
reliability
suggestibility
suggestive interview
memory

memory

\begin{abstract}
A b s t r a c t
The aim of the study was to determine the influence of authority on the susceptibility of child witnesses and the reliability of their testimonies. This study, consisting of experimental and control groups, included 20 girls and 20 boys, totalling 40 children. It took place in two phases; an initial phase ("eyewitness", "post-event interview”) and, one week later, a final phase ("recall"). In the individual interviews held with the children, a questionnaire consisting of a free narrative question and 18 open-ended questions was used. The free narrative question asked the children to specify the details they remembered about the animated film. The open-ended questions focused on the events and characters in the film. However, 12 of the open-ended questions could be answered correctly since they were about characters and situations in the film that the children had watched, while six of the questions were trick questions that were about characters and situations that were not shown in the film. For data analysis, both quantitative and qualitative methods were used to reach the deeper level of perception and memories that children shared about the film. In conclusion, after analysis, it was found that even when the interview takes place immediately after the event, children are significantly affected by the misinformation given by an adult and their knowledge on the event in question is shaped according to this misinformation. It was observed that children create "a new event" based on the information they receive from an adult.
\end{abstract}

\section{Introduction}

Binet observed in research he carried out with children in 1900 that they preferred to give wrong answers about the facts they did not remember about a specific event in order to satisfy the interviewer, even though the first studies of eyewitness testimony were aimed at adults (Binet, 1900). He also indicated that children are prone to confirm adults' interpretations of events and replace their own memory with incorrect memory and remarked within the framework of these results that children are open to social suggestion (Binet, 1900).

Varendonck is one of the first psychologists to research directivity in children. In a study he conducted with children, he told them a story about the school garden then asked them to describe a person approaching them in the same garden. He concluded that children's memory could easily be manipulated, because seventeen children out of twenty-two who participated in the study indicated that they had met the fictitious person described in the story (Varendonck, 1911). Some children not only remembered they had met this imaginary person, but they also named this imaginary person and described what he looked like.

Lipmann (1911) presented a different opinion in the same year. He indicated in his studies that he believed there were no differences between the memories of a child and an adult. Lipmann stated that children remember events and facts differently because they are more attentive to the small details which adults ignore. However, he also specified that children who perceive adult interviewers as an authority tend to agree with the suggestions in questions on aspects, they were not sure about. 
The scientific literature about children's eyewitness testimony, starting with Binet (1900) and supported by the contributions of other researchers, developed slowly until the 1980s. At this time, children took part more frequently in the judicial system both as witnesses and as victims due to the increase in child abuse cases, so studies on child witnesses gained importance. Foley and Johnson (1985) worked with children aged six in their studies on memory and recall. They concluded that children remembered things that did not actually take place when they were asked to describe events (Foley and Johnson, 1985).

Another study conducted on children's memory performance was carried out by Ceci and Bruck (1993). They concluded that children were more easily manipulated than adults, and found it difficult to distinguish reality from imagination. They found that the event memories of children were more influenced by misinformation given after the event (Ceci and Bruck, 1993) than the event memories of adults. They emphasised that children with weak memories were more vulnerable to misinformation from an external source. and more influenced by orientation when it comes to deteriorating memories. They also found that children said what they thought the interviewer would like them to say. Similarly to Ceci and Bruck (1993), Gudjonsson and Sigurdsson (2003) explained the concept of "obeying the authority" and emphasized that children tended to make incorrect statements to "satisfy" the interviewer or to act in an expected manner even though they had remembered what actually happened.

Having called attention to repeated interviews held with child witnesses, Gulotta et al. (1996) observed that children could change their statements to satisfy the interviewer even after the first interview.

In the light of the research cited that focused on the reliability of child witness testimonies, this study aimed to determine the influence of authority on the susceptibility of child witnesses and the reliability of their testimonies.

\section{Method}

\subsection{Participants and Procedure}

As the study included individual interviews with children aged 9, permission to interview them was obtained from the Institutional Ethics Committee at Faculty of Cerrahpasa Medicine, Istanbul University. In addition, informed consent was obtained from the children's parents and/or fosters.

This study, consisting of experimental and control groups, included 20 girls and 20 boys, totalling 40 children. It took place in two phases; an initial phase and, one week later, a final phase.
In the initial phase, children were shown a 4-minute animated film called Boundin by Pixar. This animated film had been used with children aged 6 to 10 in a study conducted by Pezdek et al. (2009). Each child was then interviewed individually.

The first stage of the initial phase was the film-watching session or "eyewitness" stage. The second stage, or "post-event interview" stage, was the interviewing of the children and recording of their responses on a questionnaire.

Prior to the individual interviews for the experimental group, an assistant researcher was introduced to the children. During the initial phase, straight after the film-watching session ended, the researcher left the room, telling the child that she would return as soon as possible and the assistant researcher would be with the child in the meantime. The period of time for which the assistant researcher stayed with each child was planned so that the assistant researcher could tell them an incorrect version of what they had seen in the film. This was structured carefully so it was identical for every child and included falsified details of the witnessed events and details which did not actually exist in the film. At the end of this period, the researcher returned to the room and the assistant researcher left the room. The researcher then interviewed the child.

Children in the control group were interviewed by the researcher directly after watching the film. This research design aimed to determine how the misinformation given by an authority figure would affect the child's event memory.

One week after the initial interviews, each child was interviewed again in the final phase or "recall" stage of the study. The animation film was not watched again during the final phase, but the same questions as those in the first phase were asked.

\subsection{Measures}

In the individual interviews held with the children, a questionnaire consisting of a free narrative question and 18 openended questions was used. The questionnaire used was the questionnaire created by Pezdek et al. (2009) translated into Turkish.

The free narrative question asked the children to specify the details they remembered about the animated film. The openended questions focused on the events and characters in the film. However, 12 of the open-ended questions could be answered correctly since they were about characters and situations in the film that the children had watched, while six of the questions were trick questions that were impossible to answer correctly as they 
were about characters and situations that were not shown in the film..

\subsection{Data Analysis}

The criteria used to score the free narrative question were the same for the first and second interviews. Accordingly, it was possible to compare the number of right and wrong answers given by each child to the free narrative question during the first and second interviews.

One point was given for every unique piece of information, whether it was correct or incorrect. So, one point was added to the right answer total for each correct statement and one point was added to the wrong answer total for every mistake or invented answer. The answers given were in categories such as event, character, clothing, time and location.

If words with a similar meaning were used more than once, only one point was given for these words. For instance, for an answer such as "he was sad, he was sorry," only one point was given. Only one point was given for identifying each character in the film, no matter how many times they were referred to. The chronological order of events was taken into account for scoring the sense of time. Each statement in which the correct sense of time was indicated received one correct answer point. However, one point was added to the wrong answer total for a mistake in the chronological order.

Additionally, for the experimental group, it was also examined how many similarities there were between their answers and the false information provided by the assistant researcher.

The answer key for the open-ended questions was generated using the film's written transcript. Even though a 3-option scoring scale consisting of the answers "true", "false" and "I don't know" was deemed suitable for evaluating the answers at the beginning of the process, it attracted our attention that the answers received from the children consisted of more than one suggestion and/or description (true or false) as the result of the interviews. It was believed that the true or false answers given with a single suggestion and/or description should not be included in the same scoring with the answers that consisted of more than one detail in the context of the aspects we studied within the context of the study, and including different evaluation in the scope would yield more meaningful results. For this reason, a "detailed answer" section was created for true and false answers that consisted of more than one suggestion (The rabbit told the lamb, "It doesn't matter what colour you are, what's important is that you're healthy, don't worry, just jump and play") or more than one description (The rabbit was wearing a black hat with white stripes) according to the purpose of the question for the evaluation of open-ended questions. Within this context, for the evaluation of the open-ended questions, a 7-option rating consisting of true and false answers, detailed true and false answers, true and false answers with more than two details, and the answer "I don't know" was used.

A scoring scale consisting of the options "false answer with more than two details", "detailed false answer", "false answer", "I don't know, I don't remember", "correct answer", "detailed correct answer" and "correct answer with more than two details" was prepared for 12 open-ended questions that can be answered in relation to the details given in the film. Evaluations were carried out according to the options "false answer with more than two details", "detailed false answer", "false answer", "I don't know, I don't remember" and "correct answer" for the 6 trick questions that were not related to the film. However, since some questions had only one correct answer (how many snakes were there, how many owls were there, etc.) no details were sought in these questions.

SPSS 17.0 program was used for statistical analysis. Since the obtained data did not show a normal distribution, hypotheses were tested using Mann Whitney U Test, Wilcoxon Test and Marginal Homogeneity Test. Chi-Square Test was used for comparison between the groups. The level of significance in this study was taken as .05. Qualitative data analysis was used to determine the deviation in the interviews of the experimental group, as well.

\section{Results}

\subsection{Evaluation of Free Narrative Question}

As the result of the obtained findings, since the $\mathrm{p}$-value for the first comparison of the control group was $<0.01$ a significant difference was found between the numbers of correct answers of the first and last interviews (Table 1).

Table 1. Comparison of the True and False Answers in the First and Last Interviews of the Control Group 


\begin{tabular}{|c|c|c|c|c|c|c|c|}
\hline & & & AO & $\mathbf{N}$ & SD & $\mathbf{Z}$ & $\mathbf{P}^{1}$ \\
\hline \multirow{3}{*}{$\begin{array}{l}\text { Control } \\
\text { Group }\end{array}$} & & Correct Answer Point_1 & 7.2000 & 20 & 2.56700 & & \\
\hline & $\begin{array}{l}\text { Comparison of the } \\
\text { First Interview }\end{array}$ & Correct Answer Point_2 & 6.1500 & 20 & 2.25424 & -3.535 & $.000 * *$ \\
\hline & $\begin{array}{l}\text { Comparison of the } \\
\text { Last Interview }\end{array}$ & $\begin{array}{l}\text { Incorrect Answer Point_1 } \\
\text { Incorrect Answer Point_2 }\end{array}$ & $\begin{array}{l}1.4000 \\
1.7000\end{array}$ & $\begin{array}{l}20 \\
20\end{array}$ & $\begin{array}{l}.99472 \\
.73270\end{array}$ & -1.732 & .083 \\
\hline
\end{tabular}

1:Wilcoxon Sign test p-value $* * \mathrm{p}<0.01 * \mathrm{p}<0.05$ AO: arithmetic average SD: standard deviation

The average number of correct answers in the first interview (7.2) is higher than the average number of correct answers in the second interview (6.1). However, the incorrect answer average of the first interview in the control group was found to be 1.4 and the incorrect answer average of the second interview was found to be 1.7 .

Table 2. Comparison of the True and False Answers in the First and Last Interviews of the Experimental Group
Since the p-value for the first comparison of the experimental group was $<0.01$ a significant difference was found between the numbers of correct answers of the first and second interviews (Table 2).

\begin{tabular}{cccccccc}
\hline & & & AO & N & SD & $\mathbf{P}^{\mathbf{1}}$ \\
\hline \multirow{2}{*}{$\begin{array}{c}\text { Experimental } \\
\text { Group }\end{array}$} & Comparison of the & Correct Answer Point_1 & 6.2500 & 20 & 2.51050 & -3.367 \\
& First Interview & Correct Answer Point_2 & 4.3500 & 20 & 1.22582 & $.000^{* *}$ \\
& Comparison of the & Incorrect Answer Point_1 & 2.0000 & 20 & .91766 & -2.000 & $.046^{*}$ \\
\hline
\end{tabular}

1:Wilcoxon Sign test $\mathrm{p}$ value $* * \mathrm{p}<0.01 * \mathrm{p}<0.05$ AO: arithmetic average SD: standard deviation

The average number of correct answers in the first interview (6.25) was found to be higher than the average number of correct answers in the second interview (4.35). In addition to this, since the $\mathrm{p}$-value for the second comparison was $\mathrm{p}<0.01$, a significant difference was found between the numbers of incorrect answers of the first and second interviews, unlike the comparisons of the other groups. The average number of incorrect answers in the first interview (2.0) was found to be lower than the average number of incorrect answers in the second interview (2.55).

\section{Evaluation of Open-Ended Questions}

\subsection{Evaluation of open-ended questions that} can be answered

As indicated in Table 3, it was seen that the number of the "I don't know" answers given to the first interview decreased in the second interview and the number of incorrect answers increased.

Table 3. Detailed Comparison of the First and Second Interview Results for the Control Group

\begin{tabular}{|c|c|c|c|c|c|c|}
\hline \multirow{2}{*}{ Questions } & \multirow{2}{*}{ Answers } & \multicolumn{2}{|c|}{ 1st interview } & \multicolumn{2}{|c|}{ 2nd interview } & \multirow{2}{*}{$\frac{\text { Test }}{\mathbf{P}^{1}}$} \\
\hline & & $\mathbf{n}$ & $\%$ & $\mathbf{N}$ & $\%$ & \\
\hline \multirow{3}{*}{$\begin{array}{l}\text { [1. How many fish were swimming at the beginning of the } \\
\text { film?] }\end{array}$} & incorrect answer & 4 & $20.0 \%$ & 7 & $35.0 \%$ & \multirow{3}{*}{.083} \\
\hline & $\begin{array}{l}\text { I don't know, I don't } \\
\text { remember }\end{array}$ & 3 & $15.0 \%$ & 0 & $0.0 \%$ & \\
\hline & correct answer & 13 & $65.0 \%$ & 13 & $65.0 \%$ & \\
\hline \multirow[t]{2}{*}{ [2. Where do the animals in the film live?] } & incorrect answer & 5 & $25.0 \%$ & 7 & $35.0 \%$ & \multirow{2}{*}{.157} \\
\hline & correct answer & 15 & $75.0 \%$ & 13 & $65.0 \%$ & \\
\hline \multirow[t]{2}{*}{ [4. How many teeth are visible in the lamb's mouth?] } & incorrect answer & 4 & $20.0 \%$ & 6 & $30.0 \%$ & \multirow{2}{*}{.157} \\
\hline & correct answer & 16 & $80.0 \%$ & 14 & $70.0 \%$ & \\
\hline [5. How many snakes are there in the film?] & incorrect answer & 4 & $20.0 \%$ & 5 & $25.0 \%$ & .317 \\
\hline
\end{tabular}




\begin{tabular}{|c|c|c|c|c|c|c|}
\hline & correct answer & 16 & $80.0 \%$ & 15 & $75.0 \%$ & \\
\hline \multirow[t]{2}{*}{ [6. What does the lamb like to do?] } & incorrect answer & 3 & $15.0 \%$ & 5 & $25.0 \%$ & \multirow{2}{*}{.157} \\
\hline & correct answer & 17 & $85.0 \%$ & 15 & $75.0 \%$ & \\
\hline \multirow[t]{2}{*}{ [8. What is it that makes the lamb sad?] } & incorrect answer & 3 & $15.0 \%$ & 3 & $15.0 \%$ & \multirow{2}{*}{.89} \\
\hline & correct answer & 17 & $85.0 \%$ & 17 & $85.0 \%$ & \\
\hline \multirow{2}{*}{$\begin{array}{l}\text { [10. How did the other animals treat the lamb when the } \\
\text { lamb was feeling sad?] }\end{array}$} & incorrect answer & 2 & $10.0 \%$ & 3 & $15.0 \%$ & \multirow{2}{*}{.317} \\
\hline & correct answer & 18 & $90.0 \%$ & 17 & $85.0 \%$ & \\
\hline \multirow[t]{3}{*}{ [11. What colour was the lamb's skin?] } & incorrect answer & 9 & $45.0 \%$ & 11 & $55.0 \%$ & \multirow{3}{*}{.180} \\
\hline & $\begin{array}{l}\text { I don't know, I don't } \\
\text { remember }\end{array}$ & 2 & $10.0 \%$ & 1 & $5.0 \%$ & \\
\hline & correct answer & 9 & $45.0 \%$ & 8 & $40.0 \%$ & \\
\hline \multirow[t]{3}{*}{ [12. What colour were the lamb's eyes?] } & incorrect answer & 7 & $35.0 \%$ & 9 & $45.0 \%$ & \multirow{3}{*}{.157} \\
\hline & $\begin{array}{l}\text { I don't know, I don't } \\
\text { remember }\end{array}$ & 4 & $20.0 \%$ & 2 & $10.0 \%$ & \\
\hline & correct answer & 9 & $45.0 \%$ & 9 & $45.0 \%$ & \\
\hline \multirow{3}{*}{$\begin{array}{l}\text { [13. What did the rabbit say to the lamb to make the lamb } \\
\text { happy?] }\end{array}$} & incorrect answer & 3 & $15.0 \%$ & 5 & $25.0 \%$ & \multirow{3}{*}{.096} \\
\hline & correct answer & 13 & $65.0 \%$ & 12 & $60.0 \%$ & \\
\hline & $\begin{array}{l}2 \text { detailed correct } \\
\text { answers }\end{array}$ & 4 & $20.0 \%$ & 3 & $15.0 \%$ & \\
\hline \multirow[t]{2}{*}{ [15. How many owls were there in the film?] } & incorrect answer & 5 & $25.0 \%$ & 7 & $35.0 \%$ & \multirow{2}{*}{.165} \\
\hline & correct answer & 15 & $75.0 \%$ & 13 & $65.0 \%$ & \\
\hline \multirow[t]{3}{*}{ [17. How often will they cut the lamb's wool?] } & incorrect answer & 8 & $40.0 \%$ & 9 & $45.0 \%$ & \multirow{3}{*}{.102} \\
\hline & correct answer & 9 & $45.0 \%$ & 10 & $50.0 \%$ & \\
\hline & $\begin{array}{l}2 \quad \text { detailed } \\
\text { answers }\end{array}$ & 3 & $15.0 \%$ & 1 & $5.0 \%$ & \\
\hline
\end{tabular}

1: Marginal homogeneity test $\mathrm{p}$-value $\mathrm{p}>0.05$

Table 4. Detailed Comparison of the First and Second Interview Results for the Experimental Group

\begin{tabular}{|c|c|c|c|c|c|c|}
\hline \multirow{2}{*}{ Questions } & \multirow{2}{*}{ Answers } & \multicolumn{2}{|c|}{ 1st interview } & \multicolumn{2}{|c|}{ 2nd interview } & \multirow{2}{*}{$\frac{\text { Test }}{\mathbf{P}^{1}}$} \\
\hline & & $\mathbf{n}$ & $\%$ & $\mathbf{n}$ & $\%$ & \\
\hline \multirow{2}{*}{$\begin{array}{l}\text { [1. How many fish were swimming at the } \\
\text { beginning of the film?] }\end{array}$} & incorrect answer & 12 & $60.0 \%$ & 14 & $70.0 \%$ & \multirow{2}{*}{.157} \\
\hline & correct answer & 8 & $40.0 \%$ & 6 & $30.0 \%$ & \\
\hline \multirow[t]{3}{*}{ [2. Where do the animals in the film live?] } & correct answer & 20 & $100.0 \%$ & 16 & $80.0 \%$ & \multirow{3}{*}{.890} \\
\hline & 2 detailed correct answers & 0 & $15.0 \%$ & 3 & $15.0 \%$ & \\
\hline & $\begin{array}{l}\text { more than } 2 \text { detailed correct } \\
\text { answers }\end{array}$ & 0 & $5.0 \%$ & 1 & $5.0 \%$ & \\
\hline \multirow{2}{*}{$\begin{array}{l}\text { [4. How many teeth are visible in the } \\
\text { lamb's mouth?] }\end{array}$} & incorrect answer & 6 & $30.0 \%$ & 6 & $30.0 \%$ & \multirow{2}{*}{.900} \\
\hline & correct answer & 14 & $70.0 \%$ & 14 & $70.0 \%$ & \\
\hline \multirow{2}{*}{ [5. How many snakes are there in the film?] } & incorrect answer & 3 & $15.0 \%$ & 4 & $20.0 \%$ & \multirow{2}{*}{.317} \\
\hline & correct answer & 17 & $85.0 \%$ & 16 & $80.0 \%$ & \\
\hline \multirow{2}{*}{ [6. What does the lamb like to do?] } & 2 detailed incorrect answers & 0 & $0.0 \%$ & 2 & $10.0 \%$ & \multirow{2}{*}{$.033 *$} \\
\hline & incorrect answer & 5 & $25.0 \%$ & 7 & $35.0 \%$ & \\
\hline
\end{tabular}




\begin{tabular}{|c|c|c|c|c|c|c|}
\hline & correct answer & 15 & $75.0 \%$ & 11 & $55.0 \%$ & \\
\hline \multirow[t]{3}{*}{ [8. What is it that makes the lamb sad?] } & incorrect answer & 2 & $10.0 \%$ & 3 & $15.0 \%$ & \multirow{3}{*}{.127} \\
\hline & correct answer & 13 & $65.0 \%$ & 17 & $85.0 \%$ & \\
\hline & 2 detailed correct answers & 5 & $25.0 \%$ & 0 & $0.0 \%$ & \\
\hline \multirow{3}{*}{$\begin{array}{l}\text { [10. How did the other animals treat the } \\
\text { lamb when the lamb was feeling sad?] }\end{array}$} & incorrect answer & 1 & $5.0 \%$ & 3 & $15.0 \%$ & \multirow{3}{*}{$.022 *$} \\
\hline & correct answer & 12 & $60.0 \%$ & 17 & $85.0 \%$ & \\
\hline & 2 detailed correct answers & 7 & $35.0 \%$ & 0 & $0.0 \%$ & \\
\hline \multirow{2}{*}{ [11. What colour was the lamb's skin?] } & incorrect answer & 15 & $75.0 \%$ & 15 & $75.0 \%$ & \multirow{2}{*}{.890} \\
\hline & correct answer & 5 & $25.0 \%$ & 5 & $25.0 \%$ & \\
\hline \multirow{2}{*}{ [12. What colour were the lamb's eyes?] } & incorrect answer & 10 & $50.0 \%$ & 11 & $55.0 \%$ & \multirow{2}{*}{.317} \\
\hline & correct answer & 10 & $50.0 \%$ & 9 & $45.0 \%$ & \\
\hline \multirow{5}{*}{$\begin{array}{l}\text { [13. What did the rabbit say to the lamb to } \\
\text { make the lamb happy?] }\end{array}$} & 2 detailed incorrect answers & 1 & $5.0 \%$ & 2 & $10.0 \%$ & \multirow{5}{*}{$.001 * *$} \\
\hline & incorrect answer & 4 & $20.0 \%$ & 11 & $55.0 \%$ & \\
\hline & correct answer & 12 & $60.0 \%$ & 7 & $35.0 \%$ & \\
\hline & 2 detailed correct answers & 2 & $10.0 \%$ & 0 & $0.0 \%$ & \\
\hline & $\begin{array}{l}\text { more than } 2 \text { detailed correct } \\
\text { answers }\end{array}$ & 1 & $5.0 \%$ & 0 & $0.0 \%$ & \\
\hline \multirow{2}{*}{$\begin{array}{l}\text { [15. How many owls were there in the } \\
\text { film?] }\end{array}$} & incorrect answer & 4 & $20.0 \%$ & 7 & $35.0 \%$ & \multirow{2}{*}{.180} \\
\hline & correct answer & 16 & $80.0 \%$ & 13 & $65.0 \%$ & \\
\hline \multirow{4}{*}{$\begin{array}{l}\text { [17. How often will they cut the lamb's } \\
\text { wool?] }\end{array}$} & 2 detailed incorrect answers & 5 & $25.0 \%$ & 3 & $15.0 \%$ & \multirow{4}{*}{.140} \\
\hline & incorrect answer & 4 & $20.0 \%$ & 10 & $50.0 \%$ & \\
\hline & correct answer & 7 & $35.0 \%$ & 7 & $35.0 \%$ & \\
\hline & 2 detailed correct answers & 4 & $20.0 \%$ & 0 & $0.0 \%$ & \\
\hline
\end{tabular}

1: Marginal homogeneity test $\mathrm{p}$-value $\mathrm{p}<0.05$

As the test probability value in all questions except for the question 6 , question 10 and question 13 was $p>0.05$ no significant difference was found between the first and second interviews on a question-based assessment (Table 4).

There was a significant difference between the first and second interviews since the test value in question 6 was $\mathrm{p}<0.05$. For the relevant question item, the incorrect answer rate reached $35 \%$ in the second interview while it was $25 \%$ in the first interview, and the number of correct answers reached $55 \%$ in the second interview while it was $75 \%$ in the first interview. In addition, this number was found to be increasing in the second interview although there were no children who answered this question with a detailed incorrect answer in the first interview.

On the other hand, it seems that there was a significant difference between the first and second interviews since the test value for question 10 was $\mathrm{p}<0.05$ (Table 4). The correct answer rate reached $85 \%$ in the second interview while it was $60 \%$ in the first interview. It also attracted our attention that the rate of giving two detailed correct answers in the first interview was $35 \%$ while this rate was $0 \%$ in the second interview.

There was a significant difference between the first and second interviews since the test value in question 13 was $p<0.05$. The incorrect answer rate for this question item reached $55 \%$ in the second interview while it was $20 \%$ in the first interview. The number of correct answers was $20 \%$ in the first interview and reached $55 \%$ in the second interview.

\subsection{Evaluation of open-ended trick questions}

As the test probability value in the trick questions except for the questions 7,16 and 18 was p>0.05 no significant difference was found between the first and second interviews on a questionbased assessment (Table 5). 
Table 5. Detailed Comparison of the First and Second Interview Results for the Trick Questions of the Control Group

\begin{tabular}{|c|c|c|c|c|c|c|}
\hline \multirow{2}{*}{ Questions } & \multirow{2}{*}{ Answers } & \multicolumn{2}{|c|}{$\begin{array}{c}\text { 1st } \\
\text { interview }\end{array}$} & \multicolumn{2}{|c|}{ 2nd interview } & \multirow{2}{*}{$\frac{\text { Test }}{\mathbf{P}^{1}}$} \\
\hline & & $\mathbf{n}$ & $\%$ & $\mathbf{n}$ & $\%$ & \\
\hline \multirow{4}{*}{$\begin{array}{l}\text { [3. What is the colour of the boat in the } \\
\text { river?] }\end{array}$} & 2 detailed incorrect answers & 1 & $5.0 \%$ & 5 & $25.0 \%$ & \multirow{4}{*}{.106} \\
\hline & incorrect answer & 7 & $35.0 \%$ & 7 & $35.0 \%$ & \\
\hline & I don't know, I don't remember & 6 & $30.0 \%$ & 3 & $15.0 \%$ & \\
\hline & correct answer & 6 & $30.0 \%$ & 5 & $25.0 \%$ & \\
\hline \multirow[t]{4}{*}{ [7. How were the frogs dressed?] } & $\begin{array}{l}\text { more than } 2 \text { detailed incorrect } \\
\text { answers }\end{array}$ & 3 & $15.0 \%$ & 5 & $25.0 \%$ & \multirow{4}{*}{$.020 *$} \\
\hline & 2 detailed incorrect answers & 5 & $25.0 \%$ & 7 & $35.0 \%$ & \\
\hline & incorrect answer & 7 & $35.0 \%$ & 6 & $30.0 \%$ & \\
\hline & I don't know, I don't remember & 5 & $25.0 \%$ & 2 & $10.0 \%$ & \\
\hline \multirow[t]{5}{*}{$\begin{array}{l}\text { [9. What colour were the clothes of the } \\
\text { man in the car?] }\end{array}$} & $\begin{array}{l}\text { more than } 2 \text { detailed incorrect } \\
\text { answers }\end{array}$ & 2 & $10.0 \%$ & 1 & $5.0 \%$ & \multirow{5}{*}{.467} \\
\hline & 2 detailed incorrect answers & 3 & $15.0 \%$ & 7 & $35.0 \%$ & \\
\hline & incorrect answer & 8 & $40.0 \%$ & 5 & $25.0 \%$ & \\
\hline & I don't know, I don't remember & 5 & $25.0 \%$ & 6 & $30.0 \%$ & \\
\hline & correct answer & 2 & $10.0 \%$ & 1 & $5.0 \%$ & \\
\hline \multirow{4}{*}{$\begin{array}{l}\text { [14. What did the rabbit say to the } \\
\text { squirrel and the moles?] }\end{array}$} & 2 detailed incorrect answers & 3 & $15.0 \%$ & 7 & $35.0 \%$ & \multirow{4}{*}{.225} \\
\hline & incorrect answer & 10 & $50.0 \%$ & 8 & $40.0 \%$ & \\
\hline & I don't know, I don't remember & 5 & $25.0 \%$ & 2 & $10.0 \%$ & \\
\hline & correct answer & 2 & $10.0 \%$ & 3 & $15.0 \%$ & \\
\hline \multirow{4}{*}{$\begin{array}{l}\text { [16. What colour were the flowers of } \\
\text { the plant behind the lamb?] }\end{array}$} & 2 detailed incorrect answers & 2 & $10.0 \%$ & 1 & $5.0 \%$ & \multirow{4}{*}{$.035^{*}$} \\
\hline & incorrect answer & 7 & $35.0 \%$ & 8 & $40.0 \%$ & \\
\hline & I don't know, I don't remember & 5 & $25.0 \%$ & 3 & $15.0 \%$ & \\
\hline & correct answer & 6 & $30.0 \%$ & 5 & $25.0 \%$ & \\
\hline \multirow[t]{5}{*}{$\begin{array}{l}\text { [18. Can you describe the hat that the } \\
\text { rabbit was wearing?] }\end{array}$} & $\begin{array}{l}\text { more than } 2 \text { detailed incorrect } \\
\text { answers }\end{array}$ & - & - & 5 & $25.0 \%$ & \multirow{5}{*}{$.001 * *$} \\
\hline & 2 detailed incorrect answers & 5 & $25.0 \%$ & 5 & $25.0 \%$ & \\
\hline & incorrect answer & 7 & $35.0 \%$ & 4 & $20.0 \%$ & \\
\hline & I don't know, I don't remember & 5 & $25.0 \%$ & 3 & $15.0 \%$ & \\
\hline & correct answer & 3 & $15.0 \%$ & 3 & $15.0 \%$ & \\
\hline
\end{tabular}

1: Marginal homogeneity test $\mathrm{p}$-value $\mathrm{p}<0.05$

Even though there are no significant differences, when we look at the answer distributions of two interviews on a question basis, it is noteworthy that the "I don't know, I don't remember" answers decreased in the second interviews compared to the first interviews, and the numbers of the incorrect answers decreased and were added to the numbers of the detailed incorrect answers.
As the test probability value in the trick questions except for the questions 3 and 16 was $p>0.05$ in the experimental group, no significant difference was found between the first and second interviews on a question-based assessment (Table 6). 
Table 6. Detailed Comparison of the First and Second Interview Results for the Trick Questions of the Experimental Group

\begin{tabular}{|c|c|c|c|c|c|c|}
\hline \multirow{2}{*}{ Questions } & \multirow{2}{*}{ Answers } & \multicolumn{2}{|c|}{ 1st interview } & \multicolumn{2}{|c|}{ 2nd interview } & \multirow{2}{*}{$\frac{\text { Test }}{\mathbf{P}^{1}}$} \\
\hline & & $\mathbf{n}$ & $\%$ & $\mathbf{N}$ & $\%$ & \\
\hline \multirow[t]{3}{*}{ [3. What is the colour of the boat in the river?] } & 2 detailed incorrect answers & 0 & $0.0 \%$ & 8 & $40.0 \%$ & \\
\hline & incorrect answer & 19 & $95.0 \%$ & 12 & $60.0 \%$ & $.004 * *$ \\
\hline & correct answer & 1 & $5.0 \%$ & 0 & $0.0 \%$ & \\
\hline \multirow[t]{3}{*}{ [7. How were the frogs dressed?] } & $\begin{array}{l}\text { more than } 2 \text { detailed } \\
\text { incorrect answers }\end{array}$ & 2 & $10.0 \%$ & 5 & $25.0 \%$ & \\
\hline & 2 detailed incorrect answers & 17 & $85.0 \%$ & 15 & $75.0 \%$ & .157 \\
\hline & incorrect answer & 1 & $5.0 \%$ & 0 & $0.0 \%$ & \\
\hline \multirow[t]{3}{*}{$\begin{array}{l}\text { [9. What colour were the clothes of the man in } \\
\text { the car?] }\end{array}$} & $\begin{array}{l}\text { more than } 2 \text { detailed } \\
\text { incorrect answers }\end{array}$ & 12 & $60.0 \%$ & 15 & $75.0 \%$ & \\
\hline & 2 detailed incorrect answers & 8 & $40.0 \%$ & 4 & $20.0 \%$ & .617 \\
\hline & incorrect answer & 0 & $0.0 \%$ & 1 & $5.0 \%$ & \\
\hline \multirow{3}{*}{$\begin{array}{l}\text { [14. What did the rabbit say to the squirrel and } \\
\text { the moles?] }\end{array}$} & 2 detailed incorrect answers & 12 & $60.0 \%$ & 5 & $25.0 \%$ & \\
\hline & incorrect answer & 7 & $35.0 \%$ & 15 & $75.0 \%$ & .197 \\
\hline & correct answer & 1 & $5.0 \%$ & 0 & $0.0 \%$ & \\
\hline \multirow[t]{3}{*}{$\begin{array}{l}\text { [16. What colour were the flowers of the plant } \\
\text { behind the lamb?] }\end{array}$} & $\begin{array}{l}\text { more than } 2 \text { detailed } \\
\text { incorrect answers }\end{array}$ & 5 & $25.0 \%$ & 11 & $55.0 \%$ & \\
\hline & 2 detailed incorrect answers & 10 & $50.0 \%$ & 9 & $45.0 \%$ & $.008 * *$ \\
\hline & incorrect answer & 5 & $25.0 \%$ & 0 & $0.0 \%$ & \\
\hline \multirow[t]{3}{*}{$\begin{array}{l}\text { [18. Can you describe the hat that the rabbit } \\
\text { was wearing?] }\end{array}$} & $\begin{array}{l}\text { more than } 2 \text { detailed } \\
\text { incorrect answers }\end{array}$ & 4 & $20.0 \%$ & 7 & $35.0 \%$ & \\
\hline & 2 detailed incorrect answers & 12 & $60.0 \%$ & 9 & $45.0 \%$ & .366 \\
\hline & incorrect answer & 4 & $20.0 \%$ & 4 & $20.0 \%$ & \\
\hline
\end{tabular}

1: Marginal homogeneity test $\mathrm{p}$ value $\mathrm{p}<0.05$

As the probability value in questions 3 and 16 was $\mathrm{p}<0.05$ it was determined that the answers given by the subjects to these questions in the first and second interviews were different from each other. It was seen that 1 child $(5 \%)$ gave the correct answer and 19 children (95\%) gave the incorrect answer to question 3 in the first interview, and these numbers turned into 0 correct answers, 12 incorrect answers (60\%) and 8 two detailed incorrect answers $(40 \%)$ in the second interview. In question 16, there were 5 incorrect answers (25\%), 10 two detailed incorrect answers $(50 \%)$ and 5 more than two detailed incorrect answers $(25 \%)$ in the first interview, while these numbers were found to be 0 incorrect answers, 9 two detailed incorrect answers (45\%) and 11 more than two detailed incorrect answers $(55 \%)$ in the second interview.

Another result that is important for this group according to the numerical data within the scope of the study is that the answers given by children show similarity with the manipulative information given by the assistant researcher.
It was found according to the numbers obtained via qualitative data analysis that 12 children $(60 \%)$ in the group indicated that they saw "a blue car" in the first and second interviews in the context of the free narrative question.

All children agreed that there was a "frog" in the film, and 11 out of 20 children (55\%) said the frog was wearing striped pants or a sweater.

The gender of the person who comes to take the lamb in the film is not clear, only an arm extending out of a car is visible. However, in line with the misinformation given by the assistant researcher, all children said they saw "a man" (5 children (25\%) even stated they saw more than one man) and once again in parallel with the manipulative information given to them, 5 children $(25 \%)$ indicated that "the man was wearing a white sweater (or shirt), green pants and a red hat". It was noted that 4 children (20\%) used two of these three details, 4 children $(20 \%)$ used one of the three details, and these 8 children gave answers similar to the manipulative information using different colours. 
When the answers similar to the misinformation about the rabbit were examined, it was seen that only 2 children (10\%) said that the rabbit was "black". However, it was noted that there were 18 children $(90 \%)$ indicating that the rabbit "was wearing a hat" and 11 children $(55 \%)$ indicating that the hat was "a red hat with a feather".

\section{Discussion}

The reliability of the statements of child witnesses, which is still studied today with regard to various factors, has been chosen as the main theme of the study, and this study tries to explain how the event memories of child witnesses are affected by the information given by adults.

When we examine the findings we have obtained from this study, we see that the number of the correct answers received in the first interview for the free narrative questions in both groups decreased in the second interview, and the number of incorrect answers received in the first interview increased in the second interview. When we look at the results of the open-ended questions, we see a similar result. It was observed that the number of correct answers given in the first interviews decreased in the second interviews, and the number of incorrect answers increased similarly. In addition, it was seen that the detailing rates of incorrect answers given in the second interviews increased, while the number of "I don't know, I don't remember" answers given to the trick questions in the first interviews decreased.

As a result of the aforementioned findings, firstly, we conclude that statements change as the amount of time passing after the event took place increases. Other studies discussing the negative effects of time on memory and therefore on the statements of witnesses (Loftus, 1975; Ackil \& Zaragoza, 1998; Bruck, Ceci \& Hembrooke, 1998; Zaragoza et al., 2001; Gudjonsson \& Sigurdsson, 2003; Zaragoza, Rich et.al. 2016) also support our result. For this reason, it is concluded that it is important to perform the judicial interrogations in the shortest time period after the event takes place regarding the reliability of a child's statement.

In addition, the detailing rates of the incorrect answers given in the second interviews led to the result that passing time causes the memory to drift away from the actual event and in time children may create a new reality regarding the event they witnessed. This emerges as an important detail within the scope of the findings of this study. However, since the answers given by children for trick questions are not approached within the scope of detailing criterion in other studies conducted on this subject (Ackil \& Zaragoza, 1998; Zaragoza et al., 2001; Stolzenberg \& Pezdek, 2013; Otgaar, Howe, Memon and Wang, 2014; Wilford, Chan, \&
Tuhn, 2014; Baumgartner, Strandberg \& Eslick, 2015), they do not include results on how much the memory drifts away from reality and therefore the obtained results cannot be scientifically compared.

Another dynamic that is observed to negatively affect the reliability of the child witness testimony according to individual interviews is that the child witness has difficulty in resisting the interviewer (adult). The results obtained in this context can respond to the actual starting point of this study.

First, even though it was stated before the interviews that the children could give the answers "I don't know, I don't remember" for questions they are not able to answer, very few such responses were received in the control group. However, it was seen in the distribution tables that children in the experimental group avoided giving the answers "I don't know, I don't remember" when a second adult was included in the process. At this point, the children were observed to be hesitant to state that they do not know or do not remember what happened in front of the interviewer, and they answered all questions including the trick ones to satisfy the interviewer and look good in front of the authority figure. The studies in the scientific literature (Sporer, 1982; Yates, 1987; Ceci, Ross \& Toglia, 1987; Gulotta et al., 1996; Zaragoza et al., 2001; Schwarz \& Roebers, 2006; Gombos, Pezdek \& Haymond, 2012; Stolzenberg \& Pezdek, 2013; Otgaar, Howe, Memon and Wang, 2014) support this result we obtained. When we discuss the contents of interviews held with the children in the experimental group, it is seen that children were significantly affected by the manipulative information given by the assistant researcher and the answers they gave to the questions were in accordance with the misinformation obtained from the adult.

When we compared the contents of the answers received from the children and the story flow which were prepared for the interview to be held with the group in question and included incorrect information, it was seen that 12 children stated they saw "a blue car" in the answers they gave to the free narrative question in the first and second interviews. However, it was observed that all children agreed they saw a "frog" and 11 children stated that the frog was wearing striped pants or a sweater even though there were no frogs in the film they watched. Even though in the film they watched, there is only a car that comes to take the lamb and only an arm extending out of the car is visible, children expressed that they saw a "man" in line with the misinformation they received from the assistant researcher. Additionally, in parallel with the manipulative information, it was seen that 5 children stated that "the man was wearing a white sweater (or a shirt), green pants and a red hat", 4 children used two of these three 
details and 4 children used one of these three details. Lastly, in parallel with the information provided by the assistant researcher, it was seen that only 2 children indicated that the rabbit was "black", 18 children stated that the rabbit was "wearing a hat," and 11 children indicated that the hat was "a red hat with a feather." However, the rabbit in the film is brown and is not wearing any clothes or hats.

As the result of this contextual comparison, it is concluded that even when the interview takes place immediately after the event, children are significantly affected by the misinformation given by an adult and their knowledge on the event in question is shaped according to this misinformation. It is observed that children create "a new event" based on the information they receive from an adult. From another point of view, these results are parallel to the results obtained by Schwarz and Roebers (2006) which state that children are influenced by social pressure when they testify about a certain event.

\section{Conclusion}

As a result of the study, it was seen that the use of guiding questions in judicial interviews held with child witnesses and the repeated interviews negatively affected the reliability of the statement given by the child. Therefore, it is recommended to pay attention to these aspects in interviews held with children to provide the information that is the most factual possible to be used in the judicial mechanism and to use free narrative questions that allow the child to express every detail they saw instead of guiding and yes-no questions. However, even a week-long time interval can cause children's memory to lose the details of an event that took place. This shows us that the first judicial action to be taken with the child must be taken immediately after the event or as soon as possible. From another point of view, evaluations should be conducted considering that the child may be mistaken as more time passes after the event takes place.

Lastly, even when it takes place immediately after the witnessed event, it is seen that adult guiding has a strong influence on the change of the child's reality about the event. Even though we cannot always control the adult information which we stated to have the power to change the reality of the judicial process, awareness can be created among judicial workers. Most essentially, judicial workers who will be in contact with the child in the judicial process may avoid giving details about the event during the interview held with the child, and may remain neutral in relation to the details given by the child.

Acknowledge: This research was funded by TUBITAK 2211-A National Scholarship Programme for PhD Students.

\section{References}

1. Ackil, J.K. and Zaragoza, M.S. (1998). "Memorial consequences of forced confabulation: Age differences in susceptibility to false memories." Developmental Psychology, Vol. 34, No.6, pg. 1358-1372. doi:10.1037/0012-1649.34.6.1358

2. Baumgartner, T.R., Strandberg, H.C. and Eslick, A.N. (2015). "Effects of self-confabulated misinformation on eyewitness memory" Infront Outback - Conference Proceedings, CSBS Student Research Conference, 23.

3. Binet, A. (1900). "La suggestibilité." Paris: Schleicher.

4. Bruck, M., Ceci, S.J. and Hembrooke, H. (1998). "Reliability and credibility of young children's reports: From research to policy and practice." American Psychologist, Vol. 53, pg. 136-151.

5. Ceci, S.J. and Bruck, M. (1993). "The suggestibility of the child witness: A historical review and synthesis." Psychological Bulletin, Vol. 113, pg. 403-439.

6. Ceci, S.J., Ross, D.F. and Toglia, M.P. (1987). "Age differences in suggestibility: Narrowing the uncertainties." Ceci, J., Toglia, M. P. \& Ross, D. F. (Eds.). Children's Eyewitness Memory. New York: Springer-Verlag.

7. Foley, M.A. and Johnson, M.K. (1985). "Confusions between memories for performed and imagined actions: A developmental comparison." Child Development, Vol. 56, pg. 1145-1155.

8. Gombos, V., Pezdek, K. and Haymond, K. (2012). "Forced confabulation affects memory sensitivity as well as response bias." Memory \& Cognition, Vol. 40, pg. 127-134. doi:10.3758/s13421-011-0129-5

9. Gudjonsson, G.H. and Sigurdsson, J.F. (2003). "The relationship of compliance with coping strategies and selfesteem." European Journal of Psy. Assessment, Vol. 19, pg. 117-123. doi:10.1027//1015-5759.19.2.117

10. Gulotta, G., De Cataldo, L., Pino, S. and Magri, P. (1996). "Il bambino come prova negli abusi sessuali." In C. Cabras, Psicologia della prova. Giuffrè, Milano. 157-214. 11. Lipmann, O. (1911). "Pedagogical psychology of report." Journal of Educational Psychology, Vol. 2, No. 5, pg. 253-261.

12. Loftus, E.F. (1975). "Leading questions and the eyewitness report.” Cognitive Psychology, Vol. 7, pg. 550572.

13. Otgaar, H., Howe, M., Memon, A. and Wang, J. (2014). "The development of differential mnemonic effects of false denials and forced confabulations." Behavioral Sciences and Law, Vol. 32, No.6, pg. 718-731. 
14. Pezdek, K., Lam, S.T. and Sperry, K. (2009). "Forced confabulation more strongly influences event memory if suggestions are other-generated than self-generated." Legal and Criminological Psychology, Vol. 14, pg. 241-252. doi: 10.1348/135532508X344773

15. Schwarz, S. and Roebers, C.M. (2006). "Age differences in the effects of social influence on children's eyewitness performance and their metacognitive monitoring." Journal of Experimental Child Psychology, Vol. 94, pg. 229-248. doi:10.1016/j.jecp.2006.01.003

16. Sporer, S.L. (1982). "A brief history of the psychology of testimony." Current Psychological Reviews, Vol. 2, pg. 323-339.

17. Stolzenberg, S. and Pezdek, K. (2013). "Interviewing child witnesses: The effect of forced confabulation on event memory.” Journal of Experimental Child Psychology, Vol. 114, No. 1, pg. 77-88. doi: 10.1016/j.jecp.2012.09.006

18. Varendonck, J. (1911). "Les temoignages d'enfants dans un proces retentissant." Archives de Psycholgie, Vol. 1l, pg. 129-171.

19. Wilford, M.M., Chan, J.C.K. and Tuhn, S.J. (2014). "Retrieval enhances eyewitness suggestibility to misinformation in free and cued recall." Journal of Experimental Psychology: Applied, Vol. 20, pg. 81- 93. doi:10.1037/xap0000001

20. Yates, A. (1987). "Should young children testify in cases of sexual abuse?" American Journal of Psychiatry, Vol. 144, pg. 476-480.

21. Zaragoza, M.S., Payment, K.E., Ackil, J.K., Drivdahl, S.B. and Beck, M. (2001). "Interviewing witnesses: Forced confabulation and confirmatory feedback increase false memories." Psychological Science, Vol. 12, No. 6, pg. 473 477. doi: 10.1111/1467-9280.00388

22. Zaragoza, M.S., Rich, P., Rindal, E. and DeFranco, R. (2016). "Forced fabrication and false eyewitness memories." In. False and Distorted Memories (Eds. Robert A. Nash, James Ost). London: Psychology Press. 